\title{
CCII-Based Inverse Active Filters with Grounded
}

\section{Passive Components}

\author{
Takao Tsukutani ${ }^{1}$, Yasutomo Kunugasa ${ }^{1}$ and Noboru Yabuki ${ }^{2}$ \\ 1. National Institute of Technology, Matsue College, Matsue 690-8518, Japan \\ 2. National Institute of Technology, Tsuyama College, Tsuyama 708-8509, Japan
}

\begin{abstract}
This paper introduces IAFs (inverse active filters) employing CCIIs (second generation current conveyors) and grounded passive components. The IAFs enable ILP (inverse low-pass), IBP (inverse band-pass) and IHP (inverse high-pass) characteristics by adding the circuit currents. Additionally, the circuit parameters $\omega_{0}$ and $Q$ can be set orthogonally adjusting the circuit components. The achievement example is given together with simulation results by PSPICE.
\end{abstract}

Key words: Analog circuits, inverse active filters, second generation current conveyors.

\section{Introduction}

Active circuit with high performances (i.e. high frequency operation, low power dissipation, etc.) is receiving much attention. The circuit designs employing active devices such as CCIIs (second generation current conveyors) and OTAs (operational transconductance amplifiers), etc. have been reported in the literature [1-3].

The IAF (inverse active filter) has been used to improve the characteristic deterioration in the signal transmission, and applied to the controller in some control systems, etc. In the IAF design, it is required to set the circuit parameters $\omega_{0}, Q$ and $H$ orthogonally or independently. Additionally, it is desirable to use the grounded passive components for integration. Several IAFs with active devices such as FTFNs (four-terminal floating nullors), CFOAs (current feedback operational amplifiers), the CCIIs and OTAs have been reported in the past [4-9]. The IAFs [4-7] with the FTFNs and CFOAs used ungrounded passive components on the device's properties. Moreover, a study [8] reported an IBP (inverse band-pass) filter employing the CCIIs, and it is applied to a PID

Corresponding author: Takao Tsukutani, $\mathrm{PhD}$., research field: analog signal processing. controller. However, as the x-terminal of the CCII is loaded by the capacitor, it leads to improper circuit response by the $\mathrm{x}$-terminal resistance at high frequency region. The CCII-based IAF with the mentioned points above has not yet been studied sufficiently.

This paper introduces three IAFs employing the CCIIs and grounded passive components. In the IAFs, all the $\mathrm{x}$-terminals of the CCIIs are grounded through the resistors. The filter circuits enable the ILP (inverse low-pass), IBP and IHP (inverse high-pass) characteristics by adding the circuit currents, and the circuit parameters $\omega_{0}$ and $Q$ can be set orthogonally by the circuit passive components. Additionally, the voltage-mode IAFs are presented utilizing the current-mode ones.

The design example is given with simulation results by PSPICE.

\section{CCII}

As the CCII is a current controlled current source, it is suitable for high frequency operation. Additionally, it can be applied to not only the voltage-mode circuit but also the current-mode one.

Fig. 1 shows the symbol of the CCII. This shows dual current output CCII. The CCII with MOS transistors is shown in Fig. 2. 


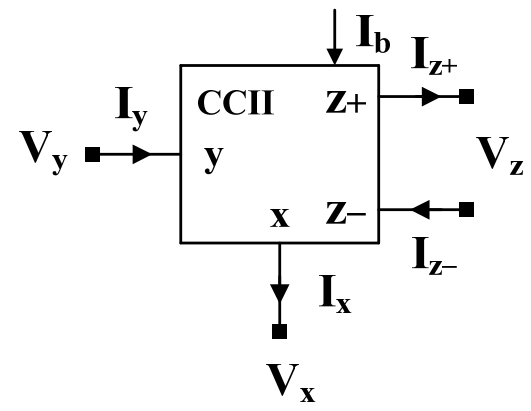

Fig. 1 Symbol of CCII.

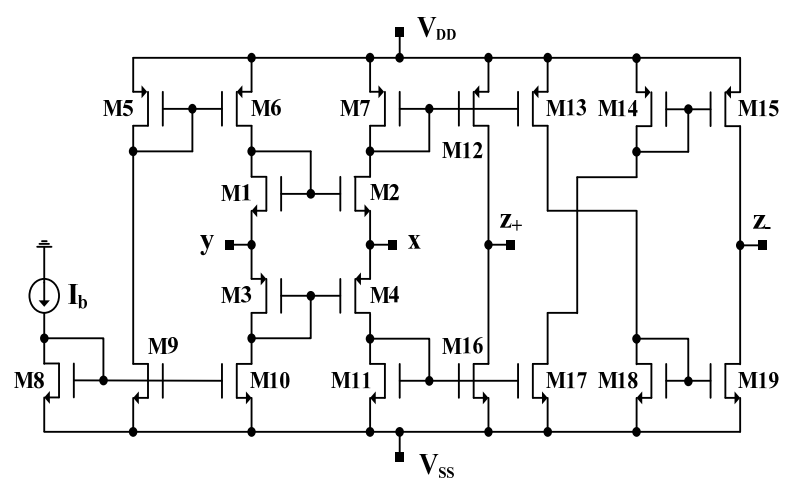

Fig. 2 CCII with MOS transistors.

The CCII is characterized by the following terminal equation [1]:

$$
\left[\begin{array}{l}
\mathrm{V}_{\mathrm{x}} \\
\mathrm{I}_{\mathrm{y}} \\
\mathrm{I}_{\mathrm{z}}
\end{array}\right]=\left[\begin{array}{ccc}
0 & 1 & 0 \\
0 & 0 & 0 \\
\pm 1 & 0 & 0
\end{array}\right]\left[\begin{array}{c}
\mathrm{I}_{\mathrm{x}} \\
\mathrm{V}_{\mathrm{y}} \\
\mathrm{V}_{\mathrm{z}}
\end{array}\right]
$$

where the sign \pm denotes the polarity of the current output $I_{\mathrm{z}}$ at z-terminal.

\section{Circuit Configuration and Analysis}

Fig. 3 shows current-mode IAF configurations. The IAFs are constructed with the CCIIs and grounded passive components. In these circuits, all the $\mathrm{x}$-terminals of the CCIIs are connected to the grounded resistors considering the parasitic resistance. Figs. 3a-3c show the ILP, IBP and IHP filters, respectively.

The circuit transfer functions $T_{\mathrm{ILP}}(\mathrm{s})\left(=I_{\mathrm{o}}(\mathrm{s}) / I_{\mathrm{i}}(\mathrm{s})\right)$ and $T_{\mathrm{IBP}}(\mathrm{s})$ in Figs. $3 \mathrm{a}$ and $3 \mathrm{~b}$ are given by:

$$
\begin{aligned}
& T_{I L P}(s)=\frac{s^{2}+\left(1 / C_{1} R_{3}\right) s+1 / C_{1} C_{2} R_{2} R_{4}}{1 / C_{1} C_{2} R_{2} R_{4}} \\
& T_{I B P}(s)=\frac{s^{2}+\left(1 / C_{1} R_{3}\right) s+1 / C_{1} C_{2} R_{2} R_{4}}{\left(1 / C_{1} R_{2}\right) s}
\end{aligned}
$$

where the current output $I_{0}(\mathrm{~s})=I_{1}(\mathrm{~s})+I_{3}(\mathrm{~s})+I_{4}(\mathrm{~s})$

The circuit parameters $\omega_{0}, Q$ and $H$ become as follows, respectively:

$$
\omega_{0}=\sqrt{\frac{1}{\mathrm{C}_{1} \mathrm{C}_{2} \mathrm{R}_{2} \mathrm{R}_{4}}}, \quad \mathrm{Q}=\mathrm{R}_{3} \sqrt{\frac{\mathrm{C}_{1}}{\mathrm{C}_{2} \mathrm{R}_{2} \mathrm{R}_{4}}}, \quad \mathrm{H}=1.0
$$

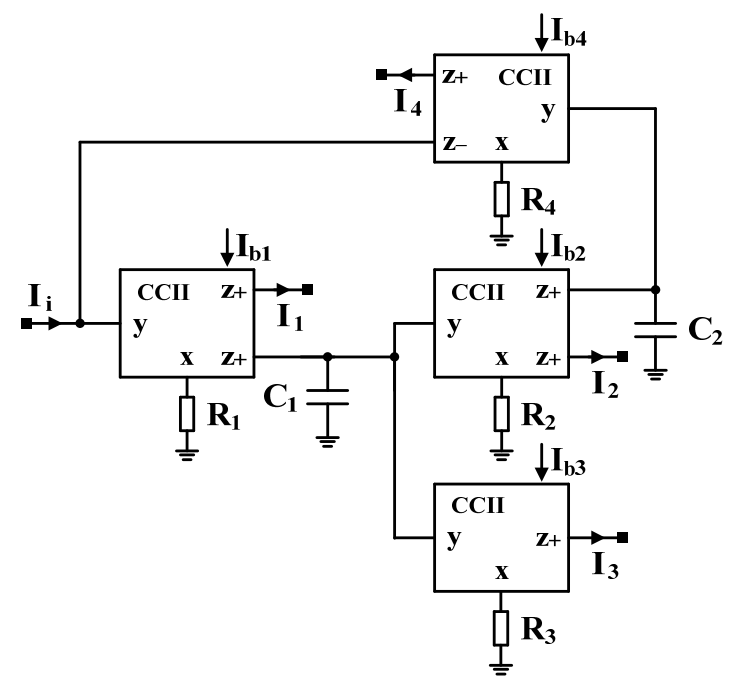

(a)

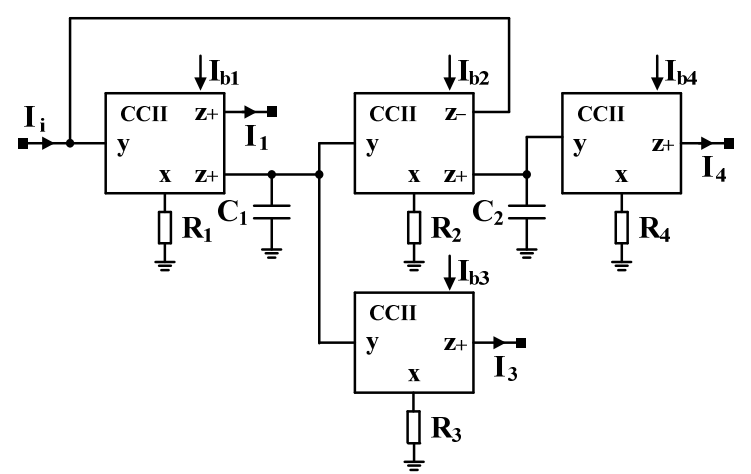

(b)

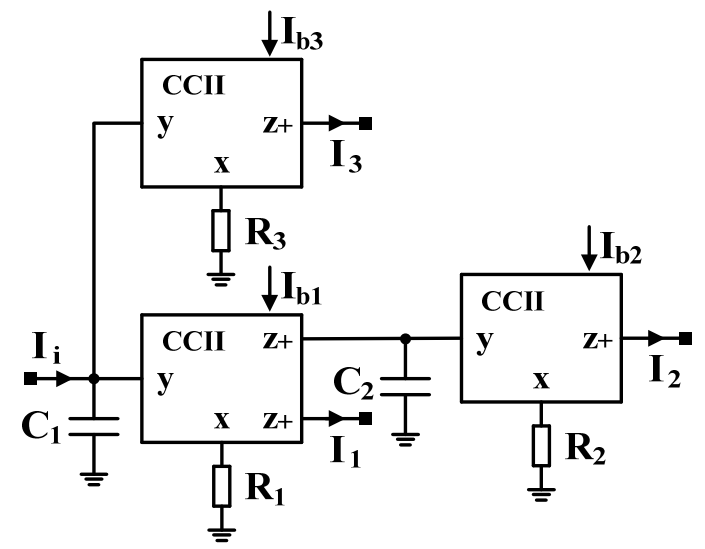

(c)

Fig. 3 Current-mode IAF configurations. 


$$
\omega_{0}=\sqrt{\frac{1}{\mathrm{C}_{1} \mathrm{C}_{2} \mathrm{R}_{2} \mathrm{R}_{4}}}, \quad \mathrm{Q}=\mathrm{R}_{3} \sqrt{\frac{\mathrm{C}_{1}}{\mathrm{C}_{2} \mathrm{R}_{2} \mathrm{R}_{4}}}, \quad \mathrm{H}=\frac{\mathrm{R}_{3}}{\mathrm{R}_{2}}
$$

Thus, the ILP and IBP characteristics can be achieved.

In Fig. $3 \mathrm{c}$, the circuit transfer function $T_{\mathrm{IHP}}(\mathrm{s})$ is given as:

$$
\mathrm{T}_{\mathrm{IHP}}(\mathrm{s})=\frac{\mathrm{s}^{2}+\left(1 / \mathrm{C}_{1} \mathrm{R}_{3}\right) \mathrm{s}+1 / \mathrm{C}_{1} \mathrm{C}_{2} \mathrm{R}_{1} \mathrm{R}_{2}}{\mathrm{~s}^{2}}
$$

where the current output $I_{\mathrm{o}}(\mathrm{s})=I_{\mathrm{i}}(\mathrm{s})+I_{2}(\mathrm{~s})+I_{3}(\mathrm{~s})$.

The circuit parameters $\omega_{0}, Q$ and $\mathrm{H}$ become the next equations.

$$
\omega_{0}=\sqrt{\frac{1}{\mathrm{C}_{1} \mathrm{C}_{2} \mathrm{R}_{1} \mathrm{R}_{2}}}, \quad \mathrm{Q}=\mathrm{R}_{3} \sqrt{\frac{\mathrm{C}_{1}}{\mathrm{C}_{2} \mathrm{R}_{1} \mathrm{R}_{2}}}, \quad \mathrm{H}=1.0
$$

The IHP characteristic can be realized.

Moreover, Eqs. (4), (5) and (7) above show the circuit parameters can be set orthogonally according to the circuit passive components.

The voltage-mode IAFs can be constructed with the current-mode IAFs as shown in Fig. 4. Here, the output voltage $V_{\text {out }}(\mathrm{s})$ can be obtained converting the current output $I_{\text {out }}$ of the current-mode IAF to voltage.

In the voltage-mode IAFs, the filter characteristics and circuit parameters $\omega_{0}$ and $Q$ are same as the current-mode ones. They gain constants $H_{I L P}=R_{b} / R_{a}$, $\mathrm{H}_{\mathrm{IBP}}=\mathrm{R}_{\mathrm{a}} \mathrm{R}_{3} / \mathrm{R}_{\mathrm{b}} \mathrm{R}_{2}$ and $\mathrm{H}_{\mathrm{IHP}}=\mathrm{R}_{\mathrm{a}} / \mathrm{R}_{\mathrm{b}}$, respectively. Thus, the ILP, IBP and IHP characteristics can be achieved as well as the current-mode IAFs.

\section{Design Example and Simulation Results}

As a design example, we tried to achieve current-mode ILP, IBP and IHP characteristics with $f_{0}$ $\left(=\omega_{0} / 2 \pi\right)=500 \mathrm{kHz}, \mathrm{Q}=1.0$ and $\mathrm{H}=1.0$. In this simulation, we have used a macro model of the CCII shown in Fig. 2.

The simulated ILP, IBP and IHP responses with PSPICE are shown in Figs. 5a-5c, respectively. The marks show the simulation responses, meanwhile the solid lines are the ideal ones. Here, the resistors $R_{\mathrm{i}}$, the capacitors $C_{\mathrm{i}}$, the bias current $I_{\mathrm{b}}$ and power dissipations $P$ are listed in Table 1. Also, we have set the input current and the power supply voltage

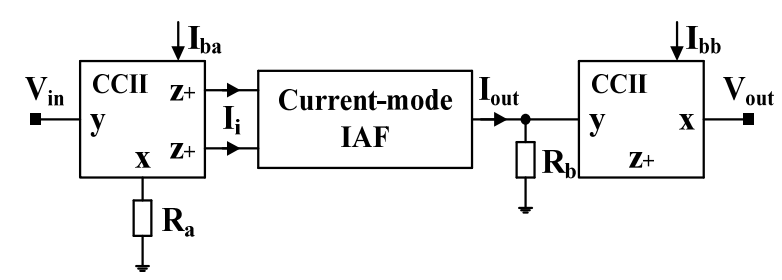

Fig. 4 Voltage-mode IAF configurations.

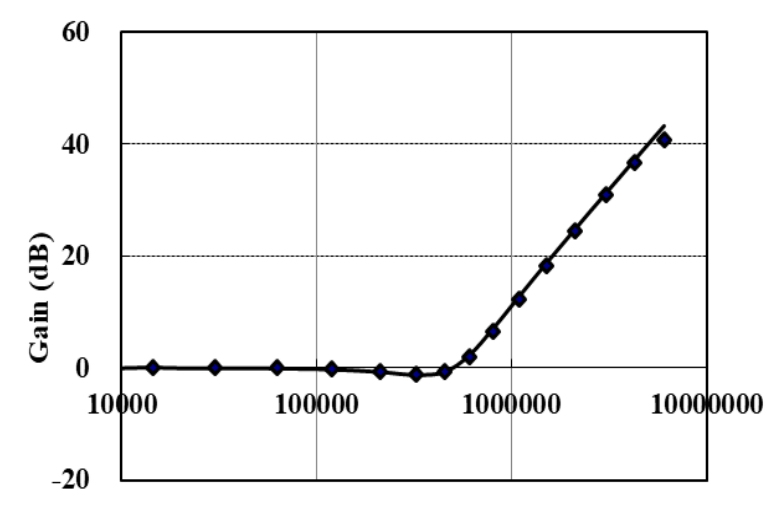

Frequency $(\mathrm{Hz})$

(a)

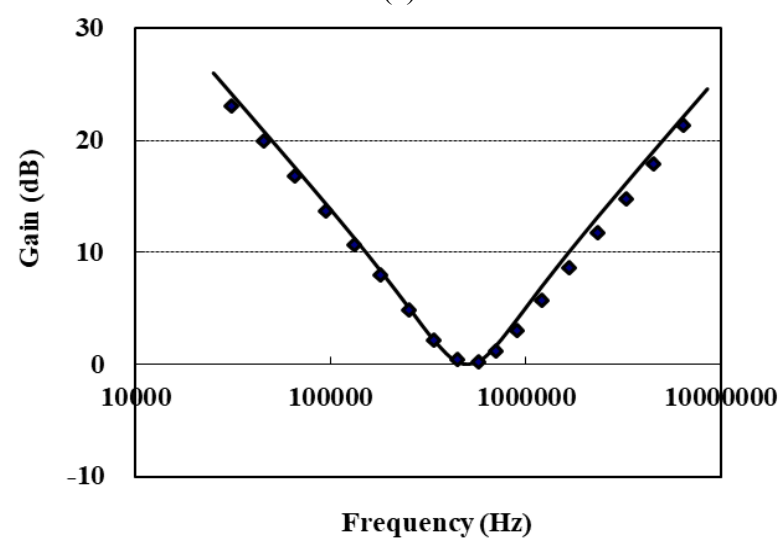

(b)

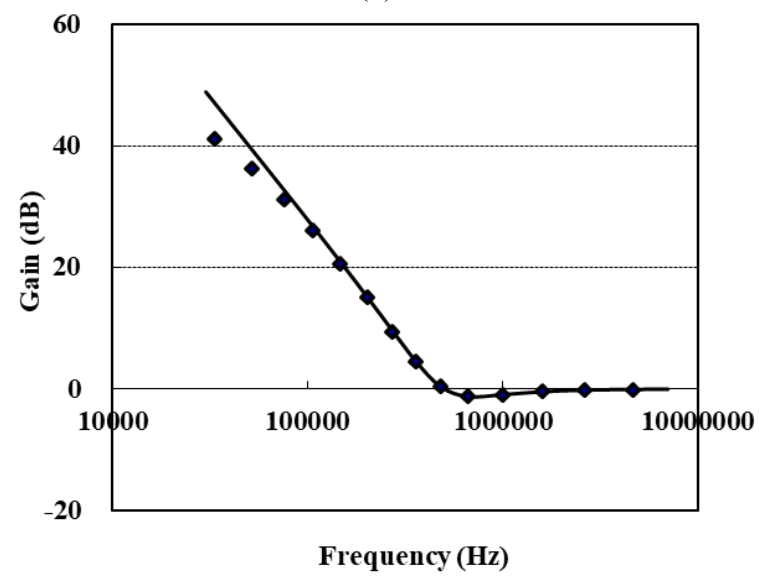

(c)

Fig. 5 Simulation responses. 
Table 1 Values of circuit elements.

\begin{tabular}{llll}
\hline Element & ILPF & IBPF & IHPF \\
\hline $\mathrm{R}_{1}(\mathrm{k} \Omega)$ & 0.1 & 1.0 & 1.0 \\
$\mathrm{R}_{2}(\mathrm{k} \Omega)$ & 14 & 12 & 1.0 \\
$\mathrm{R}_{3}(\mathrm{k} \Omega)$ & 14 & 12 & 1.0 \\
$\mathrm{R}_{4}(\mathrm{k} \Omega)$ & 14 & 12 & - \\
$\mathrm{C}_{1}(\mathrm{pF})$ & 20 & 20 & 155 \\
$\mathrm{C}_{2}(\mathrm{pF})$ & 20 & 15 & 110 \\
$\mathrm{I}_{\mathrm{b}}(\mu \mathrm{A})$ & 60 & 60 & 162 \\
$\mathrm{P}(\mathrm{mW})$ & 7.67 & 7.01 & 10.2 \\
\hline
\end{tabular}

Table 2 Sizes of MOS transistors.

\begin{tabular}{ll}
\hline Transistors & W/L \\
\hline M1-M4 & $20 \mu / 0.6 \mu$ \\
Others & $10 \mu / 2 \mu$ \\
\hline
\end{tabular}

at $I_{\mathrm{i}}=10 \mu \mathrm{A}$ and $V_{\mathrm{DD}}=-V_{\mathrm{SS}}=1.85 \mathrm{~V}$, respectively. It is found that the simulation responses are favorable enough over a wide frequency range.

The sizes of the MOS transistors are listed in Table 2. And other device parameters were used the parameters from MOSIS $0.5 \mu \mathrm{m}$.

\section{Conclusions}

The CCII-based IAFs with grounded passive components have been proposed. We have demonstrated that the IAFs enable ILP, IBP and IHP characteristics, and that the circuit parameters $\omega_{0}$ and $Q$ can be set orthogonally by the passive components. The voltage-mode IAFs have been introduced utilizing the current-mode ones. The achievement example has been given together with simulation results by PSPICE. The simulation responses have been appropriate enough over a wide frequency range. The IAF configurations are very suitable for high frequency operation and implementation in CMOS technology.

The non-idealities (e.g. voltage and current tracking errors) of the CCII affect the filter characteristics. The effect on the non-idealities must be discussed further.

\section{References}

[1] Fabre, A., Saaid, O., Wiest, F., and Boucheron, C. 1996. "High Frequency Applications Based on a New Current Controlled Conveyor." IEEE Transactions on Circuits and Systems 43 (2): 82-91.

[2] Tao, Y., and Fidler, J. K. 2000. "Electronically Tunable Dual-OTA Second-Order Sinusoidal Oscillators/Filters with Non-interacting Controls: A Systematic Synthesis Approach." IEEE Transactions on Circuits and Systems 47 (2): 117-29.

[3] Tsukutani, T., Sumi, Y., Higashimura, M., and Fukui, Y. 2003. "Current-Mode Biquad Using OTAs and CF." Electronics Letters 39 (3): 262-3.

[4] Chipipop, B., and Surakampontorn, W. 1999. "Realisation of Current-Mode FTFN-Based Inverse Filter." Electronics Letters 35 (9): 690-1.

[5] Wang, H. Y., and Lee, C. T. 1999. "Using Nullors for Realization of Current-Mode FTFN-Based Inverse Filter." Electronics Letters 35 (22): 1889-90.

[6] Abuelma'atti, M. T. 2000. "Identification of Cascadable Current-Mode Filters and Inverse-Filters Using Single FTFN." Frequenz 54 (11-12): 284-9.

[7] Gupta, S. S., Bhaskar, D. R., Senani, R., and Singh, A. K. 2009. "Inverse Active Filters Employing CFOAs." Electrical Engineering 91: 23-6.

[8] Yuce, E., Tokat, S., Minaei, S., and Cicekoglu, O. 2006. "Low-Component-Count Insensitive Current-Mode and Voltage-Mode PID, PI and PD Controllers." Frequenz 60 (3-4): 65-9.

[9] Tsukutani, T., Sumi, Y., and Yabuki, N. 2014. "Electronically Tunable Inverse Active Filters Employing OTAs and Grounded Capacitors." International Journal of Electronics Letters, online. 